\title{
Multiannual occurrence of mycotoxins in feed ingredients and complete feeds for pigs in the Czech Republic
}

\author{
Martin Svoboda ${ }^{1}$, Jana Blahová 2 , Alena Honzlová ${ }^{3}$ Jana Kalinová4, Pavla Macharáčková ${ }^{5}$, \\ Jan Rosmus ${ }^{6}$, Vít Mejzlík ${ }^{1}$, Patrik Kúkol ${ }^{1}$, Veronika Vlasáková7, Karolína Mikulková ${ }^{8}$ \\ ${ }^{1}$ University of Veterinary and Pharmaceutical Sciences Brno, Faculty of Veterinary Medicine, \\ Ruminant and Swine Clinic, Brno, Czech Republic \\ ${ }^{2}$ University of Veterinary and Pharmaceutical Sciences Brno, Faculty of Veterinary Hygiene and Ecology, \\ Department of Animal Protection, Welfare and Behaviour, Brno, Czech Republic \\ ${ }^{3}$ State Veterinary Institute Jihlava, Czech Republic, \\ ${ }^{4}$ Central Institute for Supervising and Testing in Agriculture, Brno, Czech Republic \\ ${ }^{5}$ State Veterinary Institute Olomouc, Czech Republic \\ ${ }^{6}$ State Veterinary Institute Prague, Czech Republic \\ ${ }^{7}$ State Veterinary Administration Prague, Czech Republic \\ ${ }^{8}$ University of Veterinary and Pharmaceutical Sciences Brno, Faculty of Veterinary Medicine, \\ Large Animal Clinical Laboratory, Brno, Czech Republic \\ Received February 28, 2019 \\ Accepted June 13, 2019
}

\begin{abstract}
The aim of the study was to evaluate the individual and combined occurrence of mycotoxins in feed ingredients and complete feeds for pigs in the Czech Republic in the years 2013-2017. The samples were analysed for the occurrence of aflatoxins (AF), deoxynivalenol (DON), zearalenone (ZEA), ochratoxin A (OTA), fumonisins (FUM), and T-2/H-2 toxins. The mycotoxin most commonly found in maize and small cereal grain samples was deoxynivalenol $(94 \%$ and $53 \%$, respectively). Deoxynivalenol was also the most frequent mycotoxin in all types of swine feed. The most frequent mycotoxin combinations in the total number of samples were DON + ZEA (56.63\%), DON + OTA (11.61\%) and DON + sum of T2/HT2 (9.76\%). The maximum values set by the European Commission for mycotoxin levels in feed ingredients and complete feeds were exceeded in the case of $\mathrm{AFB}_{1}$, deoxynivalenol, zearalenone, ochratoxin $\mathrm{A}$ and T-2/ H-2 toxins. Our findings support the need for further monitoring of mycotoxins in feed ingredients and complete feeds for pigs in the Czech Republic.
\end{abstract}

Aflatoxin, deoxynivalenol, zearalenone, ochratoxin, fumonisins, T-2 toxin, maize, cereals, swine

Mycotoxins represent a serious problem in swine production because they can have a major effect on the health and productivity of pigs (Chay tor et al. 2011). Mycotoxins are secondary fungal metabolites that are toxic to both animals and humans. Approximately 400 mycotoxins have been identified to date, the majority being produced by species of the genera Aspergillus, Penicillium and Fusarium (Jard et al. 2011). The contamination of agricultural commodities and feed with mycotoxins can occur under favourable conditions during plant growth, storage and harvest. The growth of fungi is influenced mainly by temperature and moisture conditions (Binder et al. 2007).

Swine belong to the species that are often affected by mycotoxins. The most important mycotoxins affecting swine health are aflatoxin (AF), deoxynivalenol (DON), ochratoxin A (OTA), zearalenone (ZEA) and fumonisins (FUM) (Chay tor et al. 2011). The contamination of swine feed can cause reduced animal productivity and immune suppression (Oswald and Comara 1998).

Various fungi can produce several mycotoxins simultaneously and commodities can also be contaminated by different fungal species. Therefore, the contamination of crops with

Address for correspondence:

Doc. MVDr. Martin Svoboda, Ph.D.

Ruminant and Swine Clinic

Faculty of Veterinary Medicine

University of Veterinary and Pharmaceutical Sciences Brno

Palackého tř. 1946/1, 61242 Brno, Czech Republic 
more than one mycotoxin is extremely common (Streit et al. 2012). Interactions between mycotoxins can be antagonistic, additive or synergistic (Monbaliu et al. 2010).

The European Union has established regulations concerning the occurrence of mycotoxins in feed ingredients and complete feeds. Commission Directive 2002/32/EC sets maximum levels for AFB1. Commission Recommendation 2006/576/EC gives maximum levels for DON, ZEA, OTA and the sum of FUM B1 and B2.

Knowledge on the mycotoxin prevalence is required for the efficient prevention of mycotoxicosis in pigs. Therefore, we decided to conduct this study in order to evaluate the individual and combined occurrence of mycotoxins in feed ingredients and complete feeds for pigs in the Czech Republic.

\section{Materials and Methods}

Samples of maize, small cereal grains and complete feeds for swine were collected from all over the Czech Republic in the years 2013-2017. They were delivered by feed producers, farmers and veterinarians. The samples were taken and prepared in compliance with the method described by the European Commission Regulation 152/2009. The samples were analysed for the occurrence of AF, DON, ZEA, OTA, FUM, and T-2 and H-2 toxins. The analyses were made according to the needs of feed producers, farmers and veterinarians. Since the samples were collected by private subjects we could not influence their choice of samples. Therefore the samples were not examined as random screening but as samples analysed based on previous suspect of contamination. Therefore each sample was analysed only for selected mycotoxins (as decided by private suppliers of samples). The individual samples were not analysed for the occurrence of all mycotoxins. The total numbers of analysed samples for particular mycotoxins are presented in Table 1. The performance of the analyses involved cooperation between four certified laboratories. The analyses were done at selected institutes (see below) by their highperformance liquid chromatography (HPLC) methods and the liquid chromatography with mass detection (LC-MS/MS) method or competitive direct enzyme-linked immunosorbent assay (ELISA) methods. Detailed procedures are subsequently listed for each workplace.

All samples were well homogenized by grinding before the analysis.

\section{ELISA tests}

Kits VERATOX by Neogen Corporation (Lansing, MI, USA) for DON, ZEA, T-2/HT-2 toxin and FUM were used for ELISA tests in the State Veterinary Institute in Jihlava.

Kits VERATOX by Neogen Corporation for T-2/HT-2 toxin and FUM were used for ELISA tests in the State Veterinary Institute in Olomouc.

Kits VERATOX by Neogen Corporation for FUM were used for ELISA tests in the State Veterinary Institute in Prague.

For determination of DON, $10 \mathrm{~g}$ of a well homogenized sample were extracted with $100 \mathrm{ml}$ of distilled water on a high-speed homogenizer for about $2 \mathrm{~min}$ or on a shaker for about $5 \mathrm{~min}$. The mixture was filtered through a microfibre glass filter paper. The filtrate was used for ELISA.

For determination of ZEA $5 \mathrm{~g}$ of a well homogenized sample was extracted with $25 \mathrm{ml}$ of mixture of methanol + water $(70+30)$ on a high-speed homogenizer for about 2 min or on a shaker for about 5 min. The mixture was filtered through a microfiber glass filter paper. This filtrate was diluted five times with distilled water (e.g. $1 \mathrm{ml}$ of filtrate $+4 \mathrm{ml}$ of distilled water), and the diluted filtrate was used for ELISA.

For determination of T-2/HT-2 toxin $5 \mathrm{~g}$ of a well homogenized sample was extracted with $25 \mathrm{ml}$ of mixture of methanol + water $(70+30)$ on a high-speed homogenizer for about 2 min or on a shaker for about $5 \mathrm{~min}$. The mixture was filtered through a microfibre glass filter paper. The filtrate was diluted $1+1$ with distilled water, and the diluted filtrate was used for ELISA.

For determination of FUM, $10 \mathrm{~g}$ of a well homogenized sample was extracted with $50 \mathrm{ml}$ of mixture of methanol + water $(70+30)$ on a high-speed homogenizer for about $2 \mathrm{~min}$ or on a shaker for about $5 \mathrm{~min}$. The mixture was filtered through a microfibre glass filter paper. This filtrate was diluted with distilled water, $7 \mathrm{ml}$ of distilled water were added to $1 \mathrm{ml}$ of the filtrate, and the diluted filtrate was used for ELISA.

The limit of quantification is $100 \mu \mathrm{g} / \mathrm{kg}$ for DON, $25 \mu \mathrm{g} / \mathrm{kg}$ for ZEA, $25 \mu \mathrm{g} / \mathrm{kg}$ for T-2/HT-2 toxin, and $200 \mu \mathrm{g} / \mathrm{kg}$ for FUM; repeatability of this method is $10-15 \%$, and recovery is $85-105 \%$.

\section{HPLC methods}

The State Veterinary Institute in Jihlava

The liquid chromatograph Waters Alliance e2695 liquid chromatograph with detectors: 2998 PDA Detector and 2475 FLR Detector were used for HPLC analysis (Waters Corporation, Milford, MA, USA).

\section{Aflatoxins}

Aflatoxins AFB1, AFB2, AFG1, AFG2 were determined after purification of the sample on an AFLAPREP 


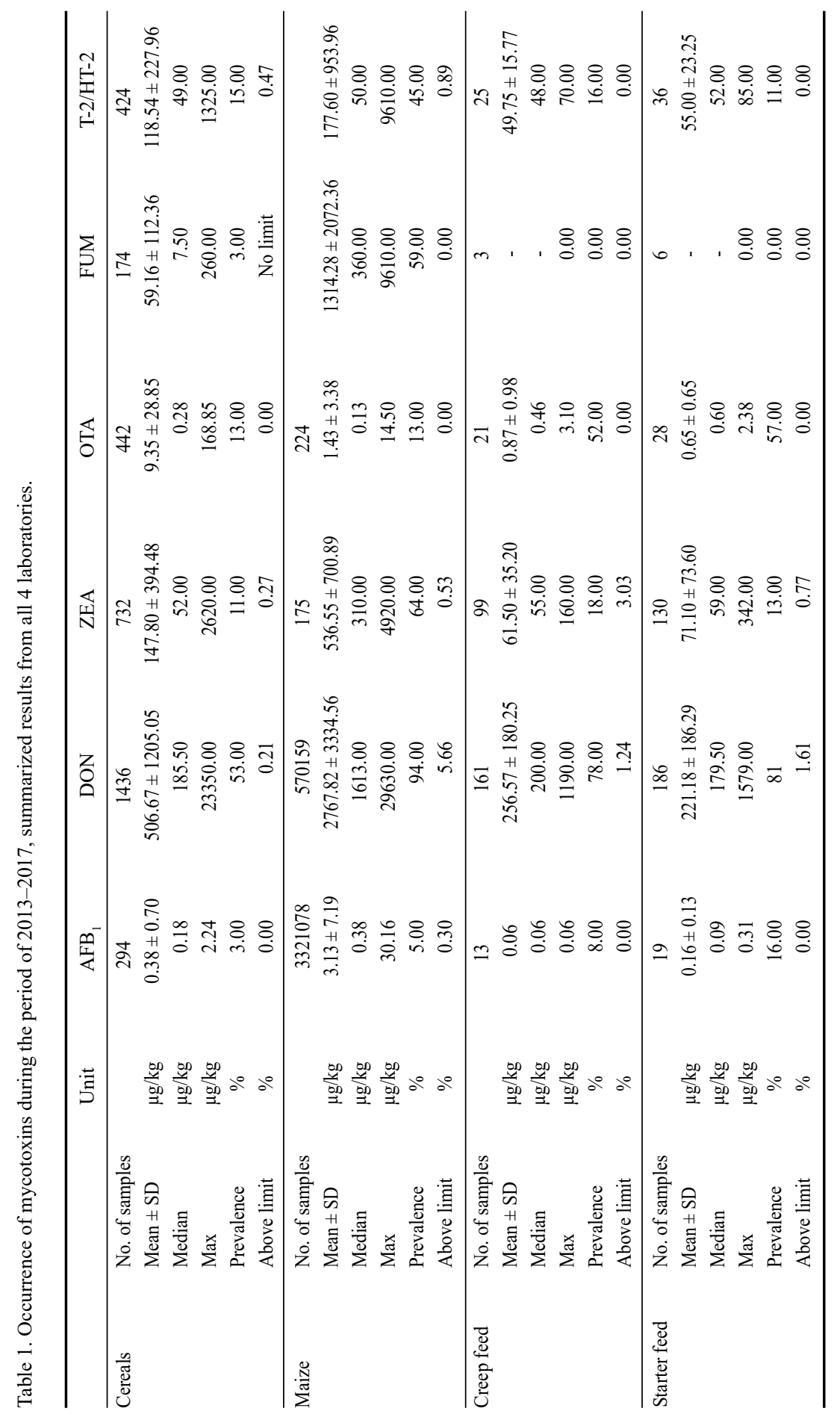




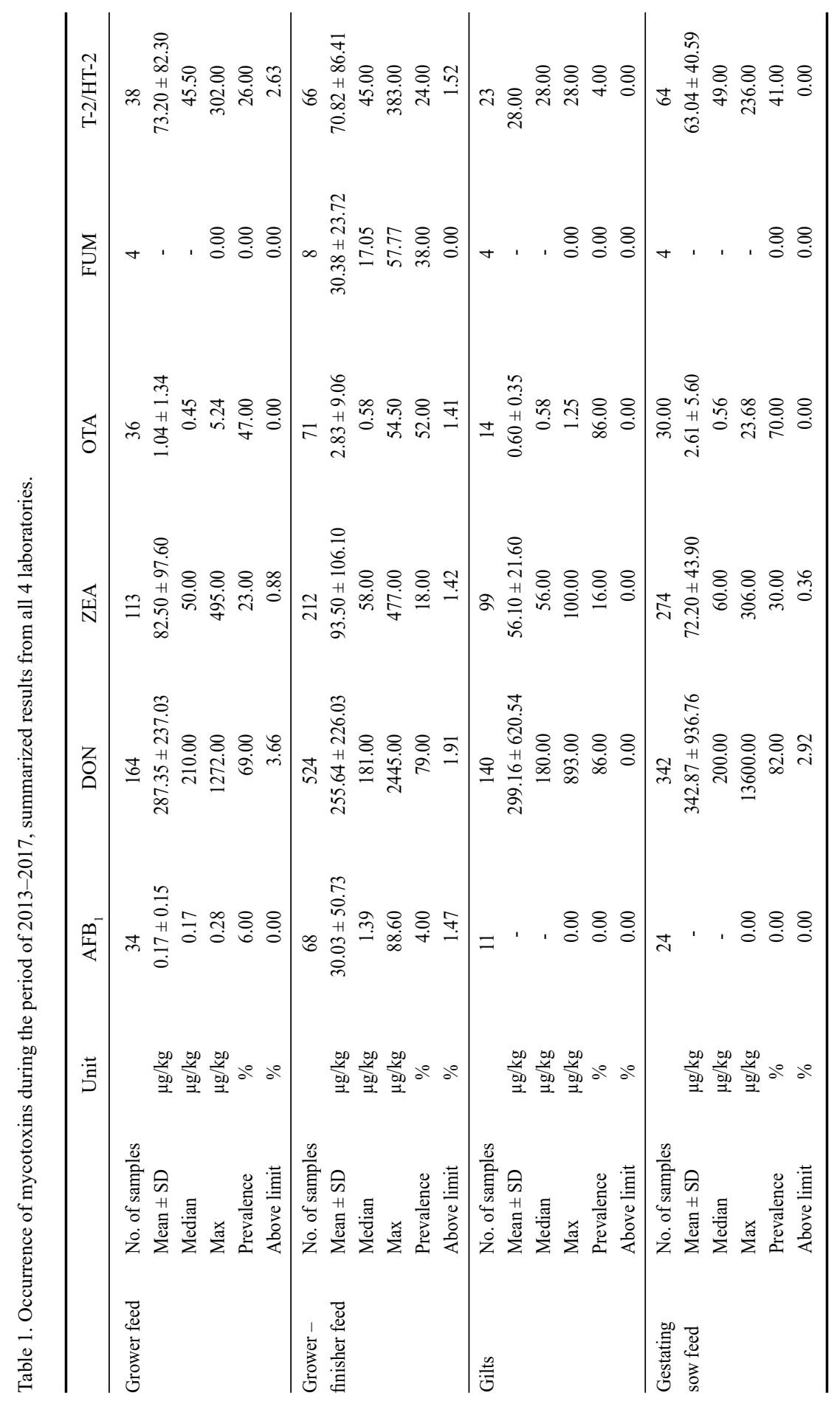




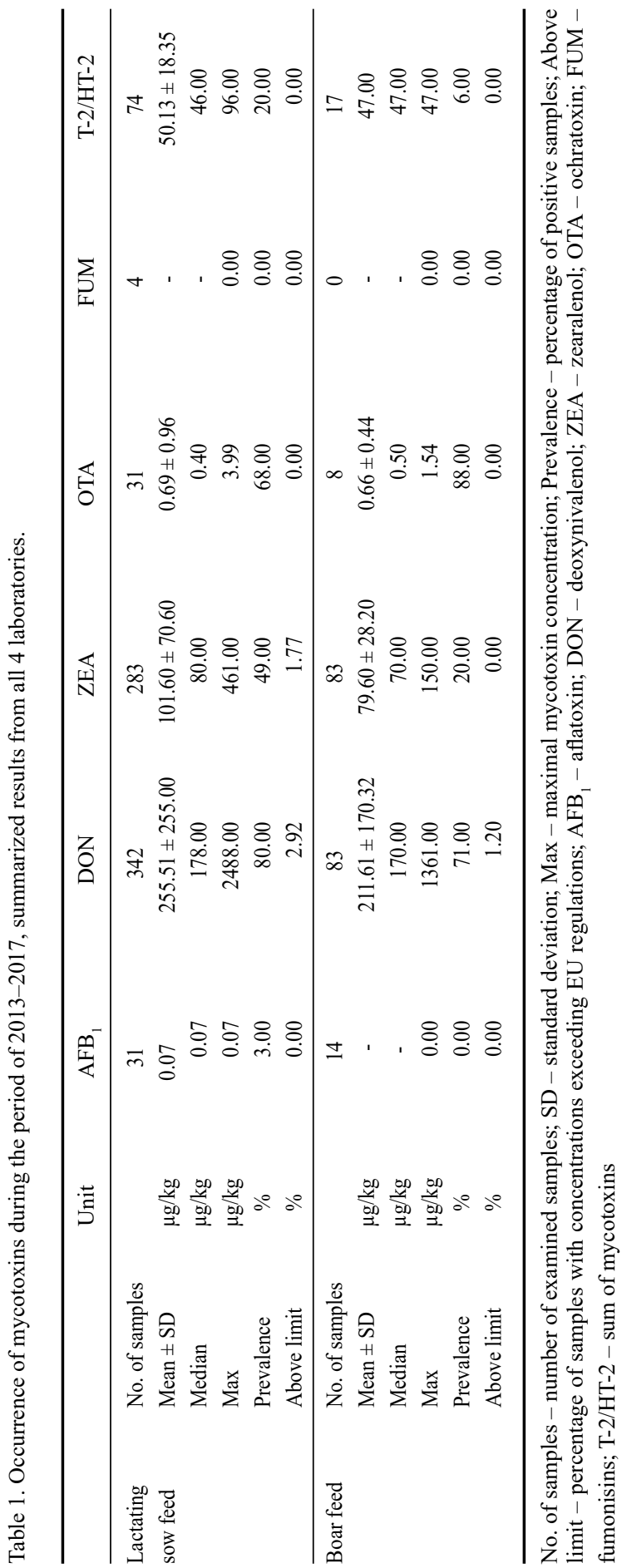

immunoaffinity column (R-Biopharm Rhone LTD, Darmstadt, Germany) by HPLC with post column derivatization using KOBRA CELL (R-Biopharm Rhone LTD) and fluorescence detection. The chromatographic analysis was performed on a Nova-Pak C18 column $(250 \mathrm{~mm} \times 4.6 \mathrm{~mm}, 4 \mu \mathrm{m})$ (Waters Corporation), mobile phase acetonitrile + methanol + redistilled water $(1+1+3)$ with the addition of potassium bromide and $4 \mathrm{~mol} / \mathrm{l}$ nitric acid solution, flow rate $1 \mathrm{ml} / \mathrm{min}$, injection volume $20 \mu \mathrm{l}$, excitation wavelength $360 \mathrm{~nm}$, emission wavelength $444 \mathrm{~nm}$, column temperature $35{ }^{\circ} \mathrm{C}$. The limit of quantification is $0.2-0.72 \mu \mathrm{g} / \mathrm{kg}$; repeatability of this method is $10 \%$ and recovery $60-100 \%$.

\section{Ochratoxin A}

OTA was determined after purification of the sample on a Neocolumn immunoaffinity column (Neogen Europe Ltd, Ayr, Scotland, UK) by HPLC with fluorescence detection. The chromatographic analysis was performed on a Nova-Pak C18 column $(250 \mathrm{~mm} \times$ $4.6 \mathrm{~mm}, 4 \mu \mathrm{m}$ ) (Waters Corporation), mobile phase acetonitrile + redistilled water + acetic acid $(99+99+2)$, flow rate $0.8 \mathrm{ml} / \mathrm{min}$, injection volume $20 \mu \mathrm{l}$, excitation wavelength $333 \mathrm{~nm}$, emission wavelength $477 \mathrm{~nm}$, column temperature $35{ }^{\circ} \mathrm{C}$. The limit of quantification is $0.06 \mu \mathrm{g} / \mathrm{kg}$; repeatability of this method is $7 \%$ and recovery $80-100 \%$.

\section{The State Veterinary Institute in Prague}

Liquid chromatography with mass detection (LC-MS/MS) was used for the analysis of the AFB1, AFB2, AFG1, AFG2 and T-2 toxins. The samples were analysed after purification $(\mathrm{NaCl}+$ acetonitrile: methanol), extraction, shaking, filtration and dilution on column $\mathrm{C} 18$ with a mobile phase $5 \mathrm{mM}$ ammonium formate $\left(\mathrm{NH}_{4} \mathrm{FAc}\right)$, $0.1 \%$ formic acid (FAc) in water and in methanol $(\mathrm{MeOH})$, injection volume $60 \mu \mathrm{l}$. The limit of quantification is $0.05 \mu \mathrm{g} / \mathrm{kg}$ for aflatoxins and $10 \mu \mathrm{g} / \mathrm{kg}$ for the T-2 toxin, the repeatability of this method is $68 \%$, and recovery $72-95 \%$.

Liquid chromatography with fluorescence detection was used for the determination of OTA and ZEA. The samples were analysed after extraction with acetonitrile: redistilled water (60:40) for OTA, with acetonitrile: redistilled water $(90: 10)$ for ZEA on a Spherisorb column $(250 \times 4 \mathrm{~mm}, 5 \mu \mathrm{m})$ (Waters Corporation) with a mobile phase redistilled water $\left(\mathrm{H}_{2} \mathrm{O}\right)$ : acetonitrile 
(ACN): acetic acid $\left(\mathrm{CH}_{3} \mathrm{COOH}\right)$ (99: 99: 2), injection volume of $100 \mu$. The limit of quantification is $0.1 \mathrm{ug} / \mathrm{kg}$ and $10 \mathrm{ug} / \mathrm{kg}$ for OTA and ZEA, respectively. Repeatability is $7.5 \%$ for OTA, and $6.5 \%$ for ZEA. Recovery is $84 \%$ and $85 \%$ for OTA and ZEA, respectively.

Liquid chromatography with diode array detection was used for the determination of DON. The samples were analysed after extraction with redistilled water on a Spherisorb column $(250 \times 4 \mathrm{~mm}, 5 \mu \mathrm{m})$ (Waters Corporation) (with a mobile phase $\mathrm{MeOH}: \mathrm{H}_{2} \mathrm{O}(15: 85)$, injection volume $50 \mu \mathrm{l}$. The limit of quantification is $100 \mu \mathrm{g} / \mathrm{kg}$, repeatability of this method is $7 \%$, and recovery $94 \%$.

The State Veterinary Institute in Olomouc

Liquid chromatographs Agilent 1100 and Agilent 1290 (Agilent Technologies, Santa Clara, CA, USA), FLD detectors and DAD detectors were used for HPLC analysis.

\section{Aflatoxins}

AFB1, AFB2, AFG1, AFG2 were determined after purification of the sample on an AFLA test immunoaffinity column (VICAM, Waters Corporation) by HPLC with post column derivatization using KOBRA CELL (R-Biopharm Rhone LTD) and fluorescence detection. The chromatographic analysis was performed on a Nova-Pak C18 column $(250 \mathrm{~mm} \times 4.6 \mathrm{~mm}, 4 \mu \mathrm{m})$ (Waters Corporation), mobile phase acetonitrile + methanol + redistilled water $(1+1+3)$ with the addition of potassium bromide and $4 \mathrm{~mol} / \mathrm{l}$ nitric acid solution, flow rate $1 \mathrm{ml} / \mathrm{min}$, injection volume $100 \mu \mathrm{l}$, excitation wavelength $362 \mathrm{~nm}$, emission wavelength $455 \mathrm{~nm}$, column temperature $25^{\circ} \mathrm{C}$. The limit of quantification is $0.1 \mu \mathrm{g} / \mathrm{kg}$, repeatability of this method is $10 \%$ and recovery $60-100 \%$.

\section{Ochratoxin A}

OTA was determined after purification of the sample on a Neocolumn immunoaffinity column (Neogen Europe Ltd) by HPLC with fluorescence detection. The chromatographic analysis was performed on a SunFire C18 column $\left(150 \mathrm{~mm} \times 3.0 \mathrm{~mm}, 3.5 \mu \mathrm{m}\right.$, Waters Corporation), mobile phase $\mathrm{ACN}+\mathrm{H}_{2} \mathrm{O}+\mathrm{CH}_{3} \mathrm{COOH}(99+99+2)$, flow rate $0.6 \mathrm{ml} / \mathrm{min}$, injection volume $50 \mu \mathrm{l}$, excitation wavelength $333 \mathrm{~nm}$, emission wavelength $477 \mathrm{~nm}$, column temperature $30{ }^{\circ} \mathrm{C}$. The limit of quantification is $0.2 \mu \mathrm{g} / \mathrm{kg}$; repeatability of this method is $8 \%$ and recovery $80-110 \%$.

\section{Deoxynivalenol}

DON was determined after purification of the sample on a DON test immunoaffinity column (VICAM, Waters Corporation) by HPLC with diode array detection. The chromatographic analysis was performed on an Ascentis Express C18 column (100 mm $\times 4.6 \mathrm{~mm}, 2.7 \mu \mathrm{m}$, Sigma Aldrich, St. Louis, MO, USA), mobile phase $\mathrm{ACN}+\mathrm{H}_{2} \mathrm{O}(10+90)$, flow rate of $0.6 \mathrm{ml} / \mathrm{min}$, injection volume of $50 \mu \mathrm{l}$, wavelength of $218.2 \mathrm{~nm}$ and $360.1 \mathrm{~nm}$, column temperature of $25^{\circ} \mathrm{C}$. The limit of quantification is $100 \mu \mathrm{g} / \mathrm{kg}$; repeatability of this method is $10 \%$ and recovery $80-100 \%$.

\section{Zearalenone}

ZEA was determined after purification of the sample on an ZEARALA test immunoaffinity column (VICAM, Waters Corporation) by HPLC with fluorescence detection. The chromatographic analysis was performed on Nova-Pak C18 column $(250 \mathrm{~mm} \times 4.6 \mathrm{~mm}, 4 \mu \mathrm{m}$, Waters Corporation $)$, mobile phase acetonitrile + redistilled water + methanol $(46+46+8)$, flow rate of $1.0 \mathrm{ml} / \mathrm{min}$, injection volume of $100 \mu \mathrm{l}$, excitation wavelength of $274 \mathrm{~nm}$, emission wavelength of $440 \mathrm{~nm}$, column temperature of $25^{\circ} \mathrm{C}$. The limit of quantification is $10.0 \mu \mathrm{g} / \mathrm{kg}$; repeatability of this method is $7 \%$ and recovery $70-100 \%$.

The Central Institute for Supervising and Testing in Agriculture, Brno, Czech Republic, National Reference Laboratory

The mycotoxins were determined by the multi-residue method of mycotoxin determination LC-MS/MS according to the Uniform Working Procedures - feed testing no. 10575.1

(http://eagri.cz/public/web/ukzuz/portal/laboratore/dokumenty-a-publikace/jednotne-pracovni-postupy/ metody-laboratorniho-zkouseni-krmiv.html).

\section{Results}

\section{Occurrence of aflatoxins}

$\mathrm{AFB}_{1}$ was detected in $5 \%$ of maize samples with a mean concentration of $3.13 \pm 7.19 \mu \mathrm{g} / \mathrm{kg}$ (max. $30.16 \mu \mathrm{g} / \mathrm{kg}$ ). AFB prevalence in small cereal grains was $3 \%$ with a mean concentration of $0.379 \pm 0.70 \mu \mathrm{g} / \mathrm{kg}(\max .2 .24 \mu \mathrm{g} / \mathrm{kg})$. In swine feed the highest prevalence was found in the starter feed $(16 \%)$. The highest mean values of $30.03 \pm 50.73 \mu \mathrm{g} / \mathrm{kg}(\max .88 .6 \mu \mathrm{g} / \mathrm{kg})$ were found in grower-finisher feed. It was determined 
that $0.30 \%$ of maize and $1.47 \%$ of grower-finisher feed samples were contaminated with $\mathrm{AFB}_{1}$ at levels exceeding the maximum value set by the European Commission Directive (2002).

\section{Occurrence of deoxynivalenol}

Deoxynivalenol was detected in $94 \%$ of maize samples with a mean concentration of $2,767.82 \pm 3,334.56 \mu \mathrm{g} / \mathrm{kg}(\max .29,630 \mu \mathrm{g} / \mathrm{kg})$. DON prevalence in small cereal grains was $53 \%$ with a mean concentration of $506.67 \pm 1,205.05(\max .23,350 \mu \mathrm{g} / \mathrm{kg})$. In swine feed the highest prevalence was found in the feed for gilts $(86 \%)$. The highest mean values of $255.64 \pm 226.03 \mu \mathrm{g} / \mathrm{kg}$ ( $\max .2,445 \mu \mathrm{g} / \mathrm{kg}$ ) were found in the grower-finisher feed. It was determined that $5.66 \%$ of maize, $0.21 \%$ of small cereal grains, $1.24 \%$ of creep feed, $1.61 \%$ of starter feed, $3.66 \%$ of grower feed, $1.91 \%$ of grower-finisher feed, $2.92 \%$ of feed for gestating sows, $2.92 \%$ of feed for lactating sows and $1.20 \%$ of boar feed samples were contaminated with DON at levels exceeding the guidance value set by the European Commission (2006).

\section{Occurrence of zearalenone}

Zearalenone was detected in $64 \%$ of maize samples with a mean concentration of $536.55 \pm 700.89 \mu \mathrm{g} / \mathrm{kg}$ (max. 4,920 $\mu \mathrm{g} / \mathrm{kg}$ ). Its prevalence in small cereal grains was $11 \%$ with a mean concentration of $147.80 \pm 394.48 \mu \mathrm{g} / \mathrm{kg}(\max .2,620 \mu \mathrm{g} / \mathrm{kg})$. In swine feed the highest prevalence was found in the feed for lactating sows (49\%). The highest mean values of $93.50 \pm 106.10 \mu \mathrm{g} / \mathrm{kg}(\max .477 \mu \mathrm{g} / \mathrm{kg}$ ) were found in the grower-finisher feed. It was determined that $0.53 \%$ of maize, $0.27 \%$ of small cereal grains, $3.03 \%$ of creep feed, $0.77 \%$ of starter feed, $0.88 \%$ of grower feed, $1.42 \%$ of grower-finisher feed, $0.36 \%$ of feed for gestating sows and $1.77 \%$ of feed for lactating sows were contaminated with ZEA at levels exceeding the guidance value set by the European Commission (2006).

\section{Occurrence of fumonisins}

Fumonisins were detected in $59 \%$ of maize samples with a mean concentration of $1,314.28 \pm 2,072.36 \mu \mathrm{g} / \mathrm{kg}$ ( $\max .9,610 \mu \mathrm{g} / \mathrm{kg})$. FUM prevalence in small cereal grains was $3 \%$ with a mean concentration of $59.16 \pm 112.36 \mu \mathrm{g} / \mathrm{kg}(\max .260 \mu \mathrm{g} / \mathrm{kg}$ ). In swine feed positive samples were found only in the grower-finisher feed $(38 \%)$ with mean values of $30.38 \pm 23.72 \mu \mathrm{g} / \mathrm{kg}(\max .57 .77 \mu \mathrm{g} / \mathrm{kg})$.

\section{Occurrence of ochratoxin A}

Ochratoxin A was detected in $13 \%$ of maize samples with a mean concentration of $1.43 \pm 3.38 \mu \mathrm{g} / \mathrm{kg}$ (max. $14.5 \mu \mathrm{g} / \mathrm{kg})$. OTA prevalence in small cereal grains was $13 \%$ with a mean concentration of $9.35 \pm 28.85 \mu \mathrm{g} / \mathrm{kg}(\max .168 .85 \mu \mathrm{g} / \mathrm{kg})$. In swine feed the highest prevalence was found in the boar feed $(88 \%)$. The highest mean values of $2.80 \pm 9.06 \mu \mathrm{g} / \mathrm{kg}$ ( $\max .54 .50 \mu \mathrm{g} / \mathrm{kg}$ ) were found in the grower-finisher feed. It was determined that $1.41 \%$ of grower-finisher feed samples were contaminated with OTA at levels exceeding the maximum value set by the European Commission (2006).

\section{Occurrence of $\mathrm{T}-2$ and $\mathrm{H}-2$ toxins}

These toxins were detected in $45 \%$ of maize samples with a mean concentration of $177.60 \pm 953.96 \mu \mathrm{g} / \mathrm{kg}$ (max. 9,610 $\mu \mathrm{g} / \mathrm{kg}$ ). The prevalence of the toxins in small cereal grains was $15 \%$ with a mean concentration of $118.54 \pm 227.96 \mu \mathrm{g} / \mathrm{kg}(\max .1,325 \mu \mathrm{g} / \mathrm{kg})$. In swine feed the highest prevalence was found in the feed for gestating sows $(41 \%)$. The highest mean values of $73.20 \pm 82.30 \mu \mathrm{g} / \mathrm{kg}(\max .302 \mu \mathrm{g} / \mathrm{kg}$ ) were found in the grower feed. It was determined that $0.89 \%$ of maize, $0.47 \%$ of small cereal grain, $2.63 \%$ of grower feed and $1.52 \%$ of grower-finisher feed samples were contaminated with T-2 and H-2 toxins at levels exceeding the maximum value set by the European Commission (2013). 


\section{Co-occurrence of mycotoxins}

The most common combinations in maize samples were DON + ZEA (63.49\%), DON + ZEA + sum of T2/HT2 (5.81\%) and DON + sum of FUM (3.02\%). The most important combinations in cereal grains samples were DON + ZEA (32.37\%), DON + OTA (20.14\%) and DON + sum of T2/HT2 $(18.71 \%)$. The most frequent combinations in swine feed samples were DON + ZEA (57.67\%), DON + OTA (19.06\%) and DON + sum of T2/HT2 $(10.40 \%)$. When counted from the total number of samples, the most frequent combinations were DON + ZEA (56.63\%), DON + OTA (11.61\%) and DON + sum of T2/HT2 (9.76\%).

\section{Discussion}

Aflatoxins (B1, B2, G1, G2) are produced mainly by Aspergilus flavus and A. parasiticus primarily in regions with tropical and subtropical climates (Pleadin 2015). These mycotoxins can infect a wide range of crops such as corn, cotton, peanuts, seeds and tree nuts (Richard 2007). Aflatoxins can alter the structure and function of proteins. The main target organ for its toxicity is the liver (Agag 2004). Pigs are among the most susceptible species. Aflatoxicosis can result in reduced growth rate, liver damage and immunosuppression (Chaytor et al. 2011). Maximum values for AFB1 of $20 \mu \mathrm{g} / \mathrm{kg}$ for feed materials, $10 \mu \mathrm{g} / \mathrm{kg}$ for complementary and complete feed and $5 \mu \mathrm{g} / \mathrm{kg}$ for compound feed for dairy cattle and calves, dairy sheep and lambs, dairy goats and kids, piglets and young poultry animals have been established (European Commission Directive 2002).

We found a similar contamination of cereals $(3 \%)$ and maize $(5 \%)$ with $\mathrm{AF}$ as that found in a Polish study. Kosicki et al. (2016) reported that 5\% of examined samples were contaminated with AF. In a study performed in Croatia, Pleadin et al. (2012) found a $13.3 \%$ prevalence of $\mathrm{AFB}_{1}$ in feed for fattening pigs with a mean concentration of $1.10 \pm 0.51 \mu \mathrm{g} / \mathrm{kg}(\max .1 .53 \mu \mathrm{g} / \mathrm{kg})$. In our study, we found a lower prevalence $(4 \%)$, though higher mean and maximum values (mean $30.03 \pm 50.73 \mu \mathrm{g} / \mathrm{kg}$, max. $88.60 \mu \mathrm{g} / \mathrm{kg}$ ), in feed for fattening pigs. In our study, $1.47 \%$ of grower-finisher feed samples were contaminated with $\mathrm{AFB}_{1}$ at levels exceeding the maximum value set by the European Commission.

Deoxynivalenol is produced by Fusarium culmorum and F. graminearum primarily in cooler climates (Pleadin 2015). It is most prevalent in temperate zones of the world such as Europe and North America (Wu 2007). It affects cereal crops such as wheat, maize and barley (EFSA 2004a). Deoxynivalenol can enter into cells and inhibit DNA, RNA, and protein synthesis (Hussein and Brasel 2001). It alters the immune response (Oswald and Comara 1998) and intestinal functions (Kolf-Clauw and Oswald 2009). Pigs are the most sensitive animals to this toxin ( $\mathrm{Wu} 2007$ ). Guidance values of $8,000 \mu \mathrm{g} / \mathrm{kg}$ for DON in cereal feed materials, $12,000 \mu \mathrm{g} / \mathrm{kg}$ for maize feed materials, $5,000 \mu \mathrm{g} / \mathrm{kg}$ for complementary and complete feeds, and $900 \mu \mathrm{g} / \mathrm{kg}$ for complementary and complete feeds for swine have been established (European Commission 2006).

In our study, we found a high prevalence of DON in cereals $(53 \%)$ and maize $(94 \%$ of samples). Compared to our study, Kosicki et al. (2016) reported a higher prevalence of DON in cereal grain samples $(98 \%)$ and a similar prevalence in maize $(89 \%)$. In a Croatian study by Pleadin et al. (2012), the DON prevalence in feed for fattening pigs was $96.6 \%$ with a mean concentration of $817 \pm 447 \mu \mathrm{g} / \mathrm{kg}(\max .1,860 \mu \mathrm{g} / \mathrm{kg})$. A Portuguese survey conducted by Almeida et al. (2011) found that $16.6 \%$ of swine feed samples (fattening pigs) contained DON at a concentration of $223.2 \pm 181.1 \mu \mathrm{g} / \mathrm{kg}$ (max. $864.0 \mu \mathrm{g} / \mathrm{kg}$ ). In our study, we found significant contamination of grower-finisher feed with DON. This was manifested by high prevalence $(79 \%)$ and mean values $(255.64 \pm 226.03 \mu \mathrm{g} / \mathrm{kg}$, max. $2,445.00 \mu \mathrm{g} / \mathrm{kg})$. In our study, $1.91 \%$ of grower-finisher feed samples were contaminated with DON at levels exceeding the maximum value set by the European Commission. 
Zearalenone is produced by Fusarium culmorum and F. graminearum worldwide and can frequently co-exist with DON (Bottalico 1998). It infects corn, wheat, barley, sorghum and rye (EF SA 2004a). The toxin has oestrogenic effects because it can bind to oestrogen receptors instead of oestradiol-17B (Pleadin 2015). The pig is the species most affected by this toxin (Chaytor et al. 2011). Intoxication in pigs can cause premature puberty, embryonic death, smaller litter sizes, weak piglets and feminization of young boars (Richard 2007). The guidance values are $2,000 \mu \mathrm{g} / \mathrm{kg}$ for ZEA in cereal feed materials, $3,000 \mu \mathrm{g} / \mathrm{kg}$ for maize feed materials, $100 \mu \mathrm{g} / \mathrm{kg}$ for complementary and complete feeds for piglets and gilts, and $250 \mu \mathrm{g} / \mathrm{kg}$ for complementary and complete feeds for sows and fattening pigs (European Commission 2006).

In our study, we found a lower prevalence of ZEA in cereals (11\%) compared to a Polish study (97\%, Kosicki et al. 2016). In maize samples, our prevalence of ZEA $(64 \%)$ was also lower to that found in the said study (92\%). In a study conducted in Croatia by Pleadin et al. (2012), ZEA prevalence in the feed for fattening pigs was $93.3 \%$ with a mean concentration of $184 \pm 21 \mu \mathrm{g} / \mathrm{kg}(\max .866 \mu \mathrm{g} / \mathrm{kg})$. The maximum recommended level was exceeded in $17 \%$ of samples. According to a Portuguese study (Almeida et al. 2011), ZEA prevalence in the feed for fattening pigs was $24.9 \%$ with a mean concentration of $18.9 \pm 17.9 \mu \mathrm{g} / \mathrm{kg}$ (max. $73.0 \mu \mathrm{g} / \mathrm{kg})$. In the feed for sows, $29.9 \%$ samples were positive for ZEA (mean $19.4 \pm 14.5 \mu \mathrm{g} / \mathrm{kg}$, $\max .57 .7 \mu \mathrm{g} / \mathrm{kg}$ ). In our study, we found a lower prevalence of ZEA in the grower-finisher feed $(18 \%)$ than the above authors. Similar prevalence $(30 \%)$ as in the Portuguese study was observed in the feed for sows. In our study, $1.42 \%$ of grower-finisher feed samples were contaminated with ZEA at levels exceeding the maximum value set by the European Commission.

Fumonisin is produced by Fusarium proliferatum and $F$. verticillioides worldwide (Richard 2007). There are three forms of the toxin - FB1, FB2, and FB3. The form FB1 is the most prevalent and harmful. The toxins mainly infect maize and its products (Pleadin 2015). Fumonisin toxicity can be explained by interference with enzyme $\mathrm{N}$-acetyl transferase which is involved in sphingolipid metabolism (Hussein and Brasel 2001). Intoxication with this toxin causes pulmonary oedema in swine (Henry and Wyatt 1993). Guidance values of $60,000 \mu \mathrm{g} / \mathrm{kg}$ for FB1 and FB2 sum in maize feed materials and $5,000 \mu \mathrm{g} / \mathrm{kg}$ for complementary and complete feeds for pigs have been established (European Commission 2006).

We found a low prevalence of FUM in cereals (3\%). This differs from the results of Kosicki et al. (2016) who detected no FUM in cereal samples. Our results $(59 \%)$ are similar to those of Kosicki et al. (2016) who reported 58\% prevalence in maize samples. Pleadin et al. (2012) found a $80 \%$ FUM prevalence in the feed for fattening pigs with a mean concentration of $405 \pm 298 \mu \mathrm{g} / \mathrm{kg}(\max .1,043 \mu \mathrm{g} / \mathrm{kg})$. In our study, we found lower prevalence (38\%) and lower mean and maximum values (mean $30.38 \pm 23.72$ $\mu \mathrm{g} / \mathrm{kg}$, max. $57.77 \mu \mathrm{g} / \mathrm{kg}$ ) in the feed for fattening pigs. According to Almeida et al. (2011) the FUM prevalence in the feed for sows was $8.7 \%$ with a mean concentration of $163.7 \pm 127.8 \mu \mathrm{g} / \mathrm{kg}$ (max. $400.0 \mu \mathrm{g} / \mathrm{kg}$ ). In our study, all samples of feed for sows were negative.

Ochratoxin A is produced by Aspergillus ochraceus and Penicillium verrucosum worldwide (Pleadin 2015). It contaminates mainly cereals, but can also be found in soybeans and peanuts (EFSA 2004b). The toxin primarily affects the kidneys causing nephropathy in pigs (Duarte et al. 2011). Guidance values of $250 \mu \mathrm{g} / \mathrm{kg}$ for OTA in cereal feed materials and $50 \mu \mathrm{g} / \mathrm{kg}$ for complementary and complete feeds for swine have been established (European Commission 2006).

We found the same prevalence of $13 \%$ in cereals and maize samples. In a study conducted in Poland by Ko sicki et al. (2016), OTA was detected in $11 \%$ of maize samples and $28 \%$ of cereals. According to Pleadin et al. (2012), OTA prevalence in the feed for fattening pigs 
was $26.6 \%$ with a mean concentration of $1.53 \pm 0.42 \mu \mathrm{g} / \mathrm{kg}(\max .2 .79 \mu \mathrm{g} / \mathrm{kg})$. Almeida et al. (2011) found that OTA prevalence in feed for fattening pigs in Portugal was $7.6 \%$ with a mean concentration of $3.9 \pm 1.2 \mu \mathrm{g} / \mathrm{kg}$ (max. $6.8 \mu \mathrm{g} / \mathrm{kg}$ ). Compared to these authors, we found a higher prevalence of OTA in the feed for fattening pigs $(52 \%)$ and $1.41 \%$ percent of the samples were contaminated with ochratoxin at levels exceeding the maximum value set by the European Commission.

The T-2 and H-2 toxins are produced by Fusarium sporotrichoides worldwide, but are most often found in northern parts of Europe such as Scandinavia and the UK (Edwards et al. 2009). They can infect maize, oats, barley, wheat, rice and soybeans (Pleadin 2015). The toxins inhibit protein and nucleic acid synthesis (Richard 2007). Swine is the species most sensitive to this toxin (Streit et al. 2012). Intoxication in pigs is manifested by a feed intake depression and a reduced weight gain (Rafai et al. 1995). Guidance values of the sum of the T-2 and HT-2 toxins of $2,000 \mu \mathrm{g} / \mathrm{kg}$ for oat milling products (husks), $500 \mu \mathrm{g} / \mathrm{kg}$ for other cereal products, and $250 \mu \mathrm{g} / \mathrm{kg}$ for compound feeds have been established (European Commission 2013).

In our study, we found a lower prevalence of the T-2 and $\mathrm{H}-2$ toxins in cereals (15\%) and maize (45\%) compared to Kosicki et al. (2016). They detected the T-2 toxin in $78 \%$ of cereals and in $67 \%$ of maize samples. Pleadin et al. (2012) reported a $46.6 \% \mathrm{~T}-2$ prevalence in the feed for fattening pigs with a mean concentration of $33.4 \pm 13.5 \mu \mathrm{g} / \mathrm{kg}(\max .78 .8 \mu \mathrm{g} / \mathrm{kg}$ ). In our study, we found a lower prevalence of $\mathrm{T}-2$ and HT-2 toxins $(24 \%)$ in the feed for fattening pigs. In our study, $1.52 \%$ of grower-finisher feed samples were contaminated with T-2 and H-2 toxins at levels exceeding the maximum value set by the European Commission.

As documented by many studies, the co-occurrence of mycotoxins is an extremely common problem in the feed industry worldwide (Streit et al. 2012). For instance, Ma et al. (2018) found that $96.4 \%$ of complete feed samples were co-infected with AFB1, ZEA, and DON. In our study, the most frequent combinations in swine feed samples were DON + ZEA (57.67\%), DON + OTA (19.06\%), and DON + SUM-T2/HT2 (10.40\%). The combination of DON + ZEA was also found to be the most frequent in the studies by Kosicki et al. (2016) and Zachariasova et al. (2014).

In general, the combined effects of mycotoxins can be additive or synergistic (Sun et al. 2014). Their implications for both animal and human health has not, however, been sufficiently investigated. The current safety legislation does not consider the toxicity of mycotoxin combinations. More studies are obviously necessary in order to produce objective data that could be considered when new safety standards are set in the future.

In general, mycotoxin concentration can be influenced by several factors that can occur under favourable conditions during plant growth, storage, and harvest. In our study, the samples were delivered by feed producers, farmers, and veterinarians according to their needs. Since they are private subjects we could not influence their choice of samples. Therefore, our study only presents the results of monitoring and makes it impossible to identify the particular reasons for higher mycotoxin concentrations.

It can be concluded based on our results that there is a need for further monitoring of mycotoxins in feed ingredients and complete feeds for pigs in the Czech Republic.

\section{Acknowledgement}

This research was supported by the Internal Grant Agency 111/2018/FVL, University of Veterinary and Pharmaceutical Sciences Brno, Czech Republic.

\section{References}

Agag BI 2004: Mycotoxins in foods and feeds: aflatoxins. Ass Univ Bull Environ Res 7: 173-205

Almeida I, Martins HM, Santos S, Costa JM, Bernardo F 2011: Co-occurrence of mycotoxins in swine feed produced in Portugal. Mycotoxin Res 27: 177-181 
Binder EM, Tan LM, Chin LJ, Handl J, Richard J 2007: Worldwide occurrence of mycotoxins in commodities, feeds and feed ingredients. Anim Feed Sci Technol 137: 265-282

Bottalico A 1998: Fusarium diseases of cereals: Species complex and related mycotoxin profiles in Europe. J Plant Pathol 80: 85-103

Chaytor AC, Hansen JA, van Heugten E, See MT, Kim SW 2011: Occurrence and decontamination of mycotoxins in swine feed. Asian Aust J Anim Sci 24: 723-738

Duarte SC, Lino CM, Pena A 2011: Ochratoxin A in feed of food-producing animals: An undesirable mycotoxin with health and performance effects. Vet Microbiol 154: 1-13

Edwards SG, Barrier-Guillot B, Clasen PE, Hietaniemi V, Pettersson H 2009: Emerging issues of HT-2 and T-2 toxins in European cereal production. World Mycotoxin J 2: 173-179

EFSA 2004a: Opinion of the Scientific Panel on Contaminants in the Food Chain on a request from the Commission related to deoxynivalenol (DON) as undesirable substance in animal feed. EFSA Journal 73: 1-42

EFSA 2004b: Opinion of the Scientific Panel on Contaminants in Food Chain on a request from the Commission related to ochratoxin A (OTA) as undesirable substance in animal feed. EFSA Journal 101: 1-36

European Commission 2002: Directive 2002/32/EC of the European Parliament and of the Council of 7 May 2002 on Undesirable Substances in Animal Feed. Off J EU 45: L140/10-L140/14

European Commission 2006: Commission Recommendation 2006/576/EC on the presence of deoxynivalenol, zearalenone, ochratoxin A, T-2 and HT-2 and fumonisins in products intended for animal feeding. Off J EU 49: L229/7-L229/9

European Commission 2009: Commission Regulation (EU) No 152/2009 laying down the methods of sampling and analysis for the official control of feed. Off J EU 52: L54/1-L54/130

European Commission 2013: Commission Recommendation 2013/165/EU on the presence of T-2 and HT-2 toxin in cereals and cereal products. Off J EU 56: L91/12-L91/15

Henry MH, Wyatt RD 1993: A review of fumonisin production by fusarium moniliforme and fumonisin toxicosis in animals. J Appl Poult Res 2: 188-192

Hussein HS, Brasel JM 2001: Toxicity, metabolism, and impact of mycotoxins on humans and animals. Toxicology 167: 101-134

Jard G, Liboz T, Mathieu F, Guyonvarc'h A, Lebrihi A 2011: Review of mycotoxin reduction in food and feed: From prevention in the field to detoxification by adsorption or transformation. Food Addit Contam Part A 28: 1590-1609

Kolf-Clauw M, Oswald IP 2009: The food contaminant, deoxynivalenol, decreases intestinal barrier function and reduces claudin expression. Toxicol Appl Pharmacol 237: 41-48

Kosicki R, Błajet-Kosicka A, Grajewski J, Twarużek M 2016: Multiannual mycotoxin survey in feed materials and feedingstuffs. Anim Feed Sci Technol 215: 165-180

Ma R, Zhang L, Liu M, Su YT, Xie WM, Zhang NY, Dai JF, Wang Y, Rajput SA, Qi DS, Karrow NA, Sun LH 2018: Individual and combined occurrence of mycotoxins in feed ingredients and complete feeds in China. Toxins 10: 113

Monbaliu S, Van Poucke C, Detavernier C, Dumoulin F, Van De Velde M, Schoeters E, Van Dyck S, Averkieva O, Van Peteghem C, De Saeger S 2010: Occurrence of mycotoxins in feed as analyzed by a multi-mycotoxin LC-MS/MS method. J Agr Food Chem 58: 66-71

Oswald IP, Comara C 1998: Immunotoxicity of mycotoxins. Rev Med Vet 149: 585-590

Pleadin J 2015: Mycotoxins in grains and feed - contamination and toxic effect in animals. Biotechnol Anim Husb 31: 441-456

Pleadin J, Zadravec M, Perši N, Vulić A, Jaki V, Mitak M 2012: Mould and mycotoxin contamination of pig feed in northwest Croatia. Mycotoxin Research, 28: 157-162

Rafai P, Bata Á, Ványi A, Papp Z, Brydl E, Jakab L, Tuboly S, Túry E 1995: Effects of various levels of T-2 toxin on clinical status, performance and metabolism of growing pigs. Vet Rec 136: 485-489

Richard JL 2007: Some major mycotoxins and their mycotoxicoses: an overview. Int J Food Microbiol 119: 3-10

Streit E, Schatzmayr G, Tassis P, Tzika E, Marin M, Taranu I, Tabuc C, Nicolau A, Aprodu I, Puel O, Oswald IP 2012: Current situation of mycotoxin contamination and co-occurrence in animal feed-focus on Europe. Toxins 4: 788-809

Sun LH, Lei MY, Zhang NY, Zhao L, Krumm CS, Qi DS 2014: Hepatotoxic effects of mycotoxin combinations in mice. Food Chem Toxicol 74: 289-293

Wu F 2007: Measuring the economic impacts of Fusarium toxins in animal feeds. Anim Feed Sci Technol 137: 363-374

Zachariasova M, Dzuman Z, Veprikova Z, Hajkova K, Jiru M, Vaclavikova M, Zachariasova A, Pospichalova M, Florian M, Hajslova J 2014: Occurrence of multiple mycotoxins in European feedingstuffs, assessment of dietary intake by farm animals. Anim Feed Sci Technol 193: 124-140 